\title{
Development of Virtual Reality-based Visual Perception and Cognitive Rehabilitation Service
}

\author{
YoHan Song, JinCheol Kim, JeongA Lee, Shin Han, YoonGyung Lim, HyunMin Lee \\ Department of Physical Therapy, College of Health Science, Honam University, Gwangju, Korea
}

Purpose: Patients with brain damage suffer from limitations in performing the activities of daily living (ADL) because of their motor function and visual perception impairment. The aim of this study was to help improve the motor function and visual perception ability of patients with brain damage by providing them with virtual reality-based contents. The usability results of the patients and specialists group were also evaluated.

Methods: The ADL contents consisted of living room, kitchen, veranda, and convenience store, similar to a real home environment, and these were organized by a rehabilitation specialist (e.g., neurologist, physiotherapist, and occupational therapist). The contents consisted of tasks, such as turning on the living room lights, organizing the drawers, organizing the kitchen, watering the plants on the veranda, and buying products at convenience stores. To evaluate the usability of the virtual reality-based visual cognitive rehabilitation service, general elderly subjects $(n=11)$, stroke patients $(n=7)$, stroke patients with visual impairment $(n=4)$, and rehabilitation specialists $(n=11)$ were selected. The questionnaires were distributed to the subjects who were using the service, and the subjective satisfaction of individual users was obtained as data. The data were analyzed using SPSS 21.0 software. The general characteristics of the users and the evaluation scores of the experts were analyzed using descriptive statistics.

Results: The usability test result of this study showed that the mean value of the questionnaire related to content understanding and difficulty was high, between 4-5 points.

Conclusion: The virtual reality rehabilitation service of this study is an efficient service that can improve the function, interest, and motivation of stroke patients.

Keywords: Cognitive therapy, Rehabilitation, Stroke, Virtual reality, Visual perception

\section{서 론}

뇌졸중 환자는 감각이상, 시지각 손상, 인지장애, 언어장애 등 다양한 증상이 나타나며, 운동기능의 상실로 움직임이나 기능을 회복하지 못해 영구적인 장애를 가지고 살아간다. 시지각 손상은 뇌졸중 환자 의 $75 \%$ 가 나타나는 신경학적 증상으로 운동학습 능력에 지장을 주 어 독립적인 일상생활을 방해한다. 또한 뇌졸중 급성기 환자의 $85 \%$ 가상지에 장애를 보이며 만성기 이후 환자에서도 $55 \%$ 이상이 상지의 기능적 제한을 가지고 있다. ${ }^{3}$ 이러한 시지각 손상과 상지의 기능적 제 한으로 인해 뇌졸중 환자들은 일상생활활동 및 사회 복귀에 어려움 을 겪는다. ${ }^{45}$ 상지의 기능적 움직임을 위해서 시각정보와 감각정보 통 합은 중요한 요소이고, 시각 조절하에 각 분절의 조화로운 움직임이
일어난다. ${ }^{6}$ 따라서 뇌졸중 환자들의 일상생활로의 복귀를 위해서는 상지능력과 시지각 기능이 통합된 능력과 훈련이 필요하다.

뇌졸중 환자의 재활은 기존의 신경발달치료(neuro developmental treatment; NDT) 접근에서 벗어나 기능적인 목적을 강조하는 접근법 으로 변화되고 있다. 국제 기능 - 장애 · 건강 분류 체계(international classification of functioning, disability and health, ICF)의 활동(activities) 과참여(participation) 항목에서 뇌졸중 환자의 문제점을 파악하고 이 를 재활의 목표로 설정하여 과제지향훈련 중재를 적용하였을 경우 기능향상이 효과적이라는 연구결과가 보고되고 있다. ${ }^{89}$ 또한, 일상으 로의 복귀를 위해서는 장애 정도에 따라 다양한 환경에서 중재가 이 루어져야 한다. 하지만 병원에서 시행되는 중재는 규격화된 치료실 환경 내에서 한정되어 있는 실정이다. ${ }^{10}$ 이러한 한계점을 보완할 수 있 
는 재활 패러다임으로 가상현실을 이용한 재활 패러다임이 제시되 고 있다. ${ }^{11}$

가상현실은 다양하고 흥미로운 가상의 환경을 환자에게 제공하 여 기존의 중재가 가지고 있는 제한점을 극복하기 위한 수단으로 사 용되고 있다. ${ }^{12}$ 가상현실을 이용한 재활훈련은 환자의 특성에 맞도록 가상환경과 수준을 쉽게 조절할 수 있으며, 다양한 감각 되먹임 제공 이 가능하고, 과제 지향적인 다양한 과제도 재현이 가능하다. ${ }^{13-15}$ 하 지만, 이러한 가상현실 재활훈련은 대부분이 $2 \mathrm{D}$ 화면에서 제공되는 균형훈련, 보행, 손 및 상지 기능에만 치우쳐져 있는 실정이고, ${ }^{16,17}$ 시 지각 인지 재활과 상지기능, 일상생활이 접목된 HMD (head mounted display) 기반 $3 \mathrm{D}$ 가상현실 시스템은 부족한 실정이다. 따라서 본 연구 에서는 뇌졸중 환자들의 기능증진 및 일상생활 활동과 사회로의 복 귀를 위해 일상생활활동과 관련된 다양한 콘텐츠로 구성된 가상현 실 기반 시지각 중심 인지 재활 서비스를 개발하고 환자 및 전문가집 단의 사용성 평가를 통해 콘텐츠 적합성을 알아보는 것이다.

사용자 경험(user experience; UX)이란 사용하거나 사용하려는 제 품, 시스템, 서비스에 대해 인식하고 반응하는 것이고 사용자가 어떠 한 환경에서 특정한 제품이나 대상을 사용하며 상호작용을 할 때 사 용자가 느끼고 체감하는 모든 과정들과 그 결과를 말한다. 좋은 UX 를 만들기 위해서는 사용성(usability), 실용성(utility). 심미성(aesthetic), 가용성(availability), 오프라인 이슈(offline issue) 등의 5 가지 요소
가 필요하다. ${ }^{18}$ 사용성 평가는 실제 사용자들이 사용하는 서비스에 대해 어떻게 생각하는지를 파악함으로써 서비스의 장점과 단점을 파악하고 사용자들이 무엇을 원하는지에 대한 정보를 얻기 위함이 다. 본 연구는 사용자 참여 및 관찰, 설문조사, 인터뷰를 일반노인과 뇌졸중 환자, 편측무시 뇌졸중 환자, 재활전문가에게 적용함으로써 가상현실 기반의 시지각 재활 서비스의 사용성 평가를 실시하여 환 자들에게 보다 나은 서비스를 제공하기 위함이다.

\section{연구 방법}

\section{1. 가상현실 기반 시지각 중심 인지재활 서비스 개발}

본 서비스는 HMD Oculus Rift와 Oculus Rift 컨트롤러를 이용한 상지 기능 및 일상생활활동, 시지각 인지능력 개선을 위한 시지각 중심의 재활서비스 콘텐츠와 환자의 재활훈련 이력관리 및 동작분석을 위 한 관리시스템, 의료기관용 서비스 중 일부 콘텐츠를 재가용으로 이 용할 수 있는 모바일 기반의 재활서비스를 개발하였다(Tion, 휴먼 IT, Korea).

본 서비스에서는 사이버 멀미(cyber sickness) 현상과 낙상의 위험도 를 줄이기 위해 모든 콘텐츠를 앉아서 시행할 수 있도록 구성하였다. 라이트 맵 베이킹(light map baking) 기술을 활용하여 프레임 드랍 (frame drop) 현상을 방지하였고 고해상도로 콘텐츠를 구현하였다. 또
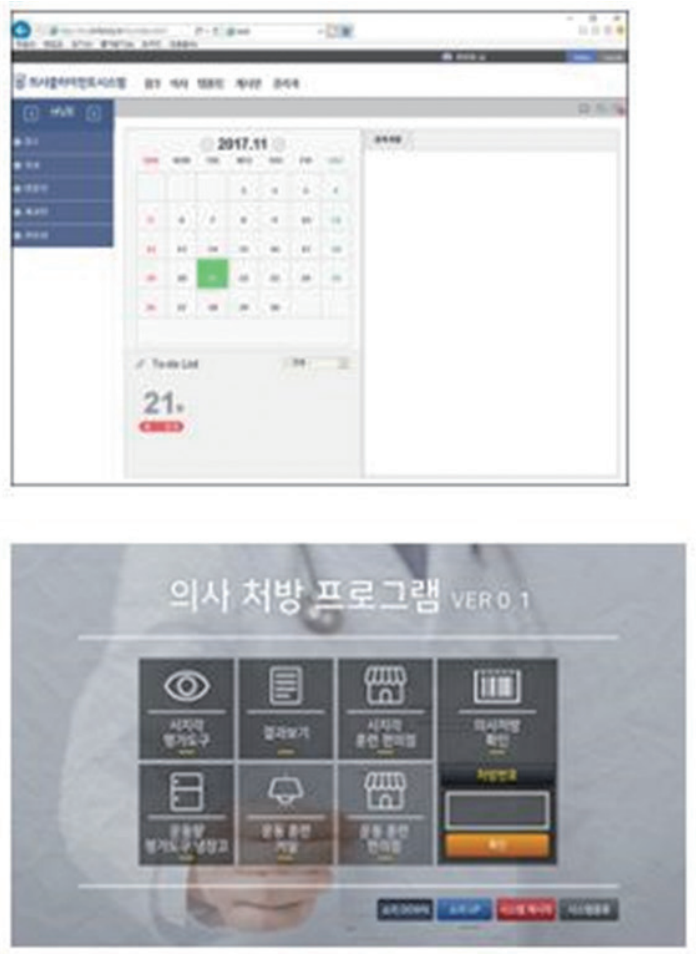
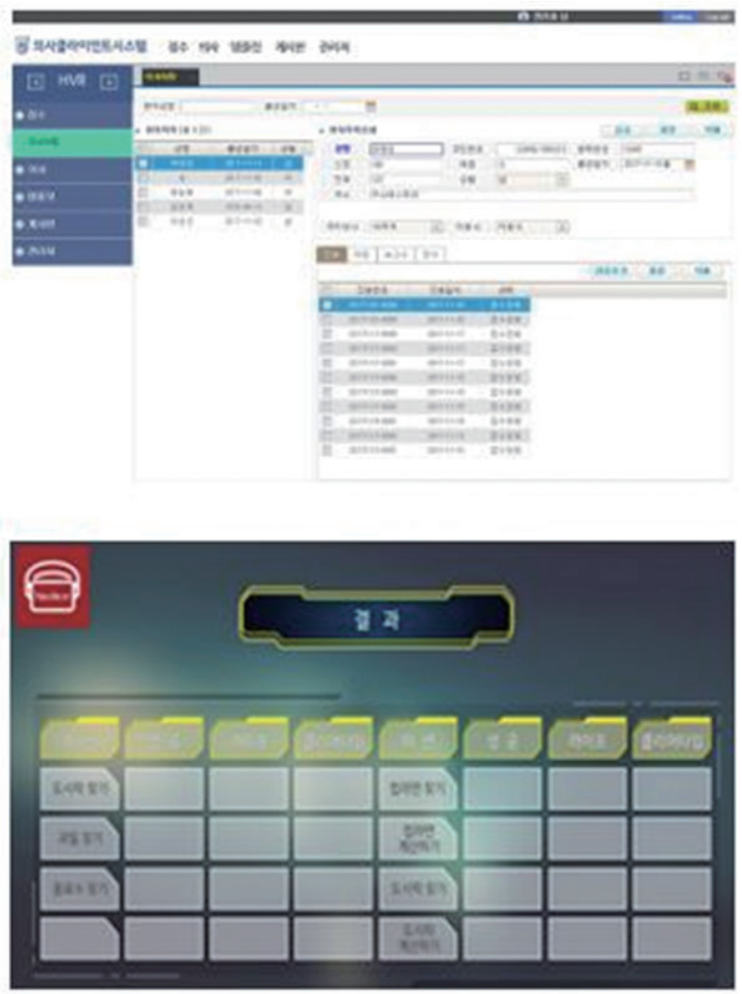

Figure 1. The picture of doctor client system. 
한, 음성지원, 캐릭터의 장소 이동 시 순간이동기능 등을 통해 사이버 멀미를 최대한 줄이도록 제작하였다.

\section{2. 관리시스템(의사 클라이언트 시스템)}

보건의료인이 시스템에 로그인을 한 후 시지각 중심 인지재활 훈련에 관한 템플릿 정보를 관리하고 환자의 훈련이력사항을 확인하며, 환 자의 상태에 따른 진단으로 재활운동훈련을 처방하는 기능과 사용 자의 현황을 직접 파악 할 수 있는 클라이언트 시스템을 개발하였다 (Figure 1). 본 시스템은 사용자의 운동 상태 및 운동량, 운동수행능력 에 대한 평가 항목들을 데이터화하여 로컬 저장소에 저장하도록 설 정하였다. 또한 재활에 대한 진행상태 및 향상된 점을 가시적으로 확 인 할수 있도록구성하였다.

\section{3. 하드웨어 시스템}

사용자가 직접 움직임을 조절할 수 있는 제스처센서와 $\mathrm{HMD}$ 를 동기 화하였으며, 구동 PC 신호에 의해 빠르게 반응하는 액추에이터시스 템을 사용하였다. Oculus Rift 컨트롤러를 적용한 HMD 연동 모션인 식기술을 적용하였고, 반복적 테스트를 통한 착용감 및 안간거리 조 절, $360^{\circ}$ 회전할 수 있는 자이로스코프 기술을 적용하였다.

\section{4. 가상현실 재활 콘텐츠 구성}

본 연구의 가상현실 재활 콘텐츠 구성은 ICF 활동과 참여 항목에 해 당하는 일상생활훈련 콘텐츠 1 종(거실, 주방, 베란다), 시지각 인지재 활 콘텐츠 1 종(편의점), 운동기능 평가도구 1 종(부억 냉장고), 시지각 평가도구 콘텐츠 14 종, 모바일 인지재활콘텐츠(모바일 편의점), 일상 생활교육 동영상 40 종으로 구성되었다. 각각의 콘텐츠는 재활전문가 (재활의학과 전문의, 신경과 전문의, 물리치료사, 작업치료사)들의 그 룹 회의를 통하여 ICF 항목과 연결시켜 뇌졸중 환자에게 필요한 일 상생활활동, 시지각 중심 인지재활 및 평가도구를 도출하여 콘텐츠 로 구성하였다.

ICF 활동과 참여 항목 중 $\mathrm{d} 1$ 학습 및 지식의 적용(learning and applying knowledge), d2일반적인 임무와 요구(general tasks and demands), $\mathrm{d} 4$ 이동(mobility), d6가정생활(domestic life), d8주요생활역역(major life areas) 5 개의 항목을 선택하였다. 선택한 영역 중 $\mathrm{dl}$ 학습 및 지식의 적 용에서는 $\mathrm{d} 110-\mathrm{d} 129$ 의 의도적 감각 경험(보기, 듣기, 여타 의도적인 지 각), d160-1179의 지식 적용(주의 집중, 사고, 연산, 문제 해결, 판단) 항 목을 추출하였고, $\mathrm{d} 2$ 일반적인 임무와 요구에서는 $\mathrm{d} 210$ 단일한 임무 수행, $\mathrm{d} 220$ 복합적 임무 수행, $\mathrm{d} 230$ 일상생활 이행 항목을 추출하였다. $\mathrm{d} 4$ 이동에서는 $\mathrm{d} 43$ 물건 나르기, 옮기기, 다루기 항목을 추출하였고,

Table 1. Virtual reality living room contents

\begin{tabular}{ccc}
\hline Living room contents Mission & Substance & ICF classification \\
\hline & Turn on the living room light $\quad$ Turn on the light by pressing the light switch d1 learning and applying knowledge, d4 carrying, mov \\
ing and handling objects
\end{tabular}

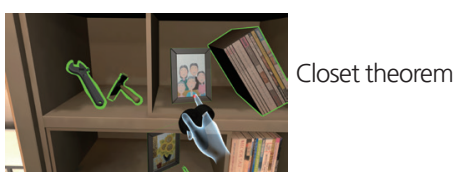

Kitchen contents

Mission

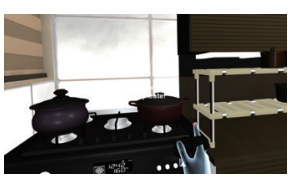

Arranging pots

Veranda contents

Mission

Substance

Place tools, books, and frames inside the closet in the marked location

Substance

Place the pots above the burner in the marked position

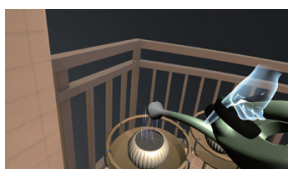

Watering the empty flowerpot using a water iris
ICF classification

d1 learning and applying knowledge, d4 carrying, moving and handling objects

ICF classification

d1 learning and applying knowledge, d4 carrying, moving and handling objects

d1 learning and applying knowledge, d4 carrying, moving and handling objects 
$\mathrm{d} 6$ 가정생활에서는 $\mathrm{d} 620$ 상품구매와 서비스 받기 항목을 추출하였 고, $\mathrm{d} 8$ 주요생활영역에서는 $\mathrm{d} 860$ 기본적인 경제적 거래를 추출하였다.

\section{(1) 일상생활훈련 콘텐츠}

일상생활훈련 콘텐츠는 일상생활과 유사한 가정환경을 가상으로 제 공하며 거실, 주방, 베란다로 구성하였다(Table 1).

\section{(2) 시지각 인지 재활 콘텐츠}

시지각 인지 재활 콘텐츠는 일상생활과 유사한 편의점을 가상으로 제공하여 다양한 미션을 수행하도록 구성하였다(Table 2).

\section{(3) 운동기능 평가도구 콘텐츠}

운동기능 평가도구 콘텐츠는 일상생활과 유사한 부억의 냉장고를 가 상으로 제공하여 어깨관절의 굽힘, 폄, 벌림, 모음 관절가동범위를 컨 트롤러의 움직임을 통해 측정할 수 있도록 구성하였다(Table 3).

\section{(4) 시지각 평가도구 콘텐츠}

시지각 평가도구 콘텐츠는 가상현실로 제공된 시야검사(visual field test). 시각운동조절(oculomotor control), 조직화하여 훝어보기(organized scanning), 시각적 부주의(visual inattention), 시각적 구별(visual discrimination), 시각적 기억(visual memory) 등의 총 14 종의 콘텐츠로 구성하였다.

\section{(5) 모바일 재활 콘텐츠}

시지각 인지 재활 콘텐츠는 Mobile HMD 기반으로 일상생활과 유사 한 가상의 편의점을 다양한 미션으로 제공하였고, 일상생활 교육 동 영상 40 종을 통해 뇌졸중 환자와 보호자가 병원 또는 가정에서 쉽게 이용할 수 있는 일상생활동작에 관련된 동작관찰훈련기반 동영상콘 텐츠 정보를 모바일 버전으로 제공하였다(Figure 2, 3) ${ }^{19}$.

\section{5. 사용성 평가}

(1) 연구대상

가상현실 기반 시지각 중심 인지재활 서비스 사용성 평가를 위해서

Table 2. Virtual reality convenience store contents

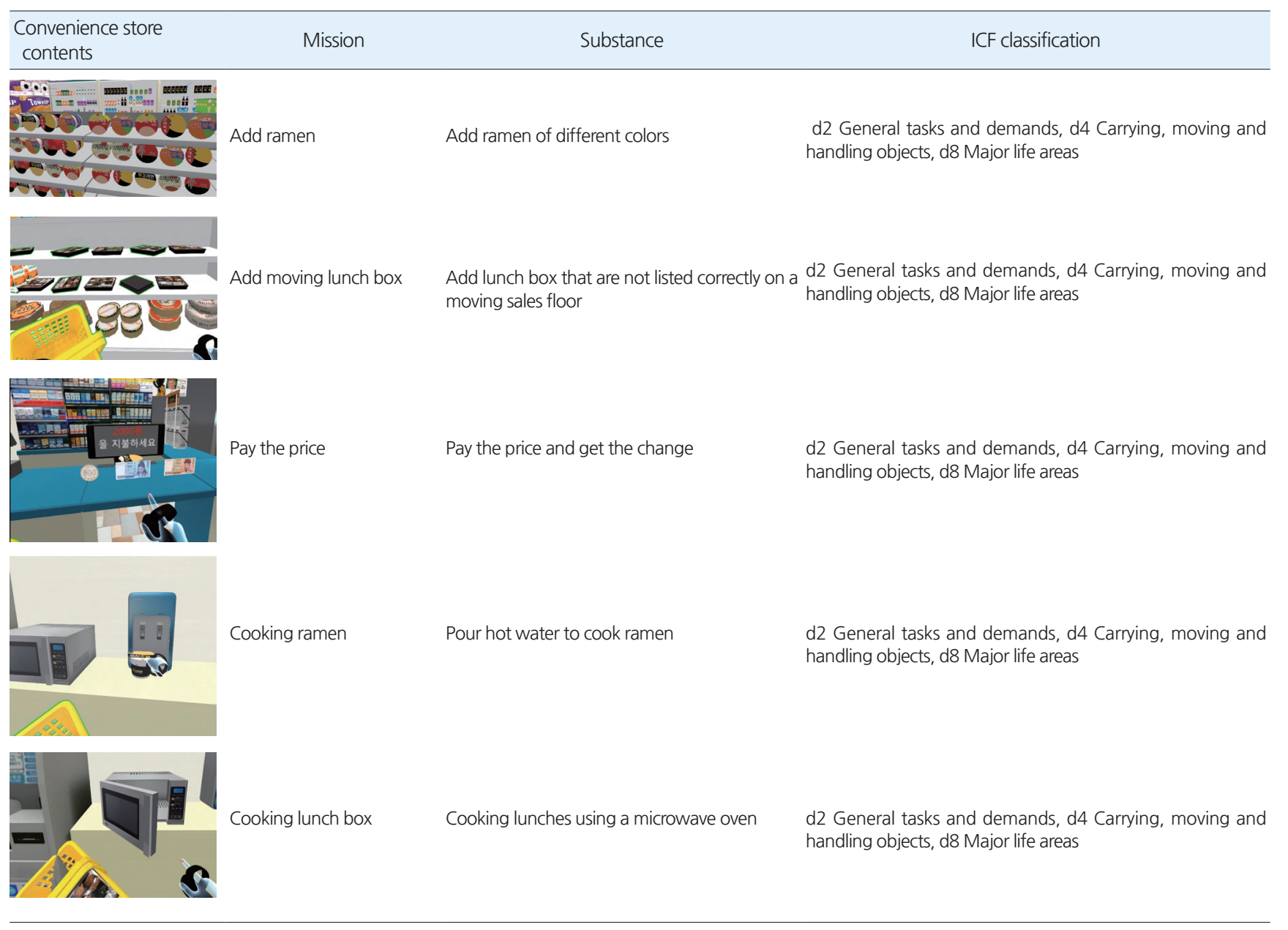


일반노인 대상자 $(\mathrm{n}=11)$, 뇌졸중 환자 $(\mathrm{n}=7)$, 편측무시 뇌졸중 환자 $(\mathrm{n}=4)$, 재활전문가 $(\mathrm{n}=11)$ 를 선정하여 연구를 진행하였다. 일반노인 대상자는 광주광역시에 위치한 $\mathrm{H}$ 복지관, 뇌졸중 환자는 $\mathrm{C}$ 요양병원 에서 시행하였다.

일반노인 대상자 선정 기준은 1.65 세 이상 노인, 2. 신경학적 병변이
없는 자, 3. 시각과 감각에 이상이 없는 자, 4. 심리적으로 불안한 증상 이 없는 자, 5. MMSE-K 점수가 24점 이상인 자. 이고, 뇌졸중 환자 선정 기준은 1 뇌졸중 진단을 받은 지 6개월 이상 경과한 자, 2. 시각과 감각 에 이상이 없는 자, 심리적으로 불안한 증상이 없는 자, MMSE-K점수 가 24 점 이상인 자이다. 편측무시 뇌졸중 환자 선정 기준은 1 . 뇌졸중

Table 3. Range of motion evaluation tool contents

Refrigerator contents $\quad$ Mission $\quad$ Move to cola in front $\quad$ both shoulder joint flexion / extension ROM
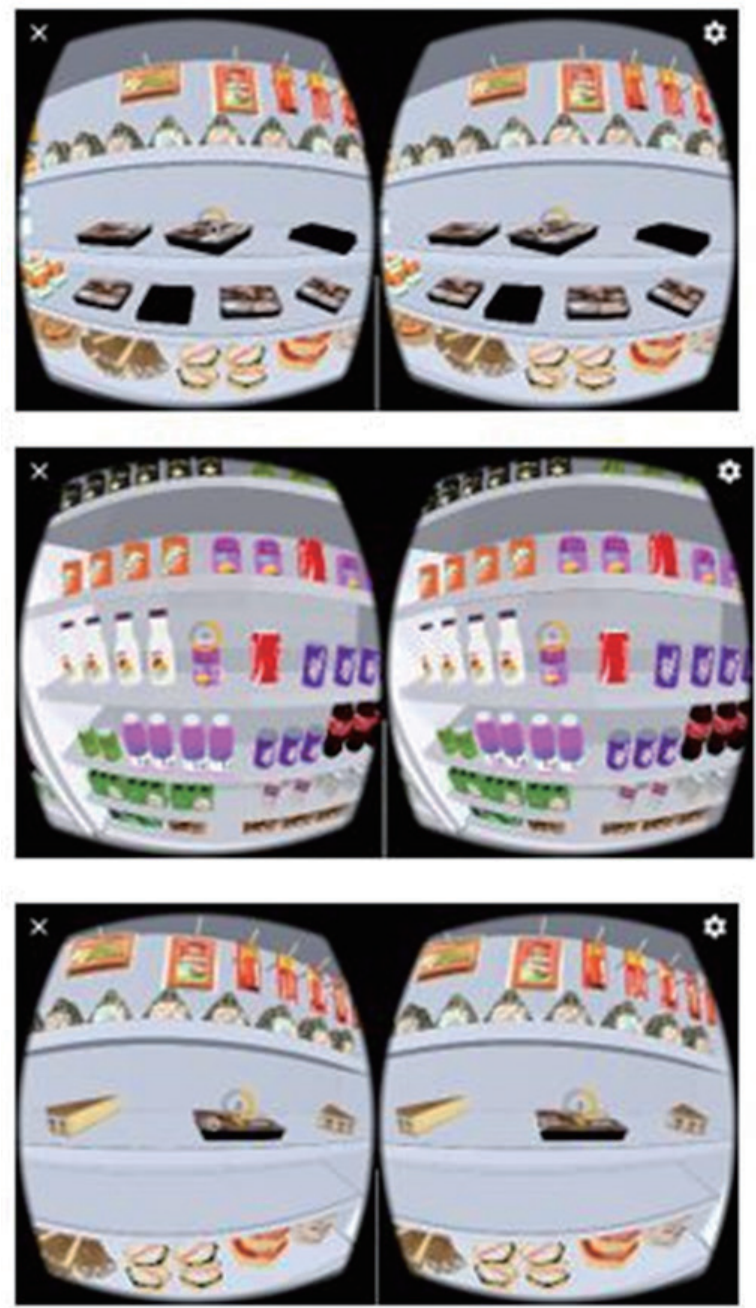
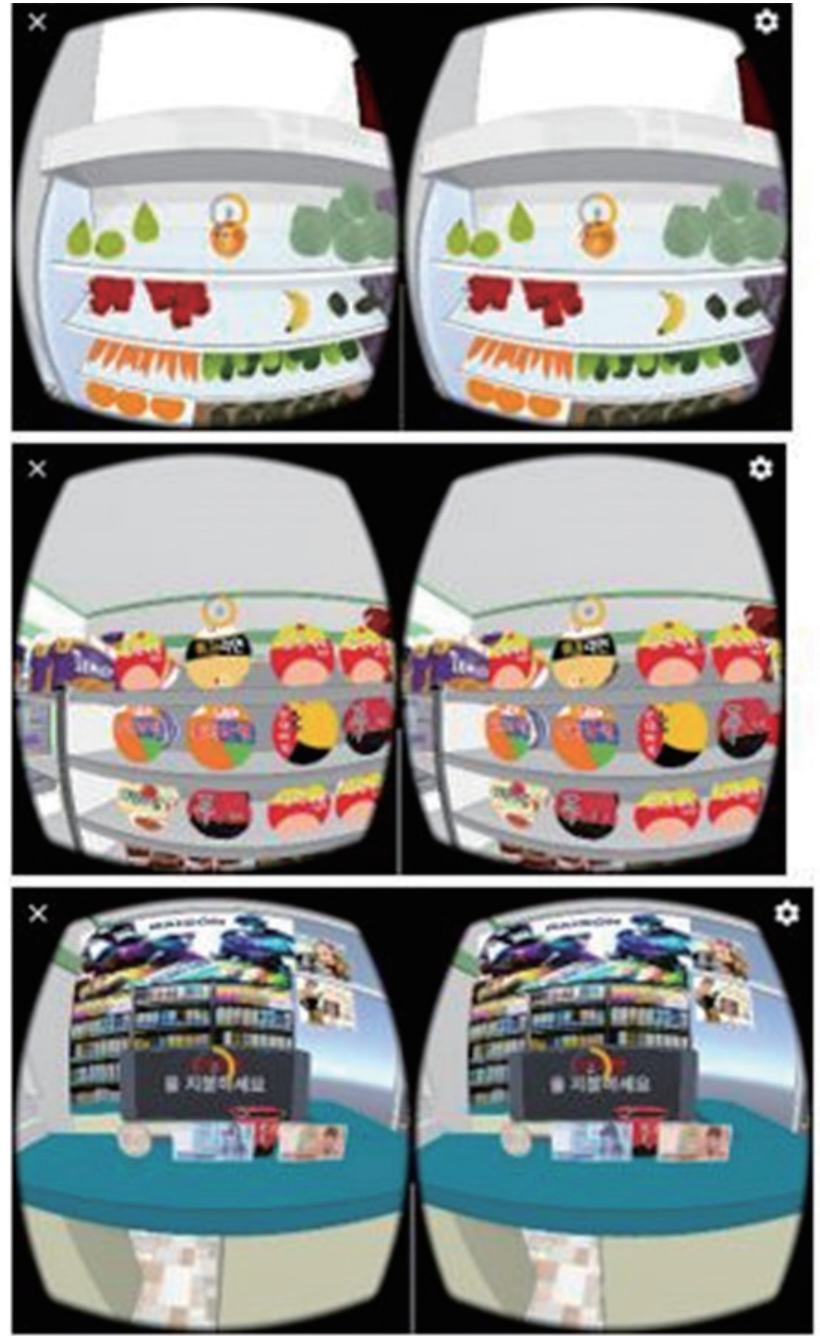

Figure 2. The pictre of mobile perception cognitive rehabilitation contents 
진단을 받은 지 6개월 이상 경과한 자, 2. 심리적으로 불안한 증상이 없는 자, $3 . \mathrm{MMSE}-\mathrm{K}$ 점수가 24 점 이상인 자, 4 . 편측무시 증상을 갖고 있는 자(선 나누기 검사, Linebisection 검사에서 약간 손상이나 심한 손상을 갖고 있는 자)로 하였다.

재활전문가는 해당분야의 전문가로 구성된 임상경력 5 년차 이상 인 재활의학과 의사, 신경과 의사, 물리치료사, 작업치료사로 선정하 였다.

\section{(2) 측정방법}

가상현실 기반 시지각 중심 인지재활 서비스 사용성 평가 방법은 일반 노인과 뇌졸중 환자, 편측무시 뇌졸중 환자, 재활전문가로 분류하였다. 각 대상자는 $\mathrm{HMD}$ 와 Controller를 착용 후 본 연구의 서비스를 15 분간 적용한 다음 설문지를 작성하여 사용자의 반응을 분석하였다.

\section{(3) 설문조사}

본 연구의 서비스 사용이 끝난 대상자에게 설문지를 배부하여 작성

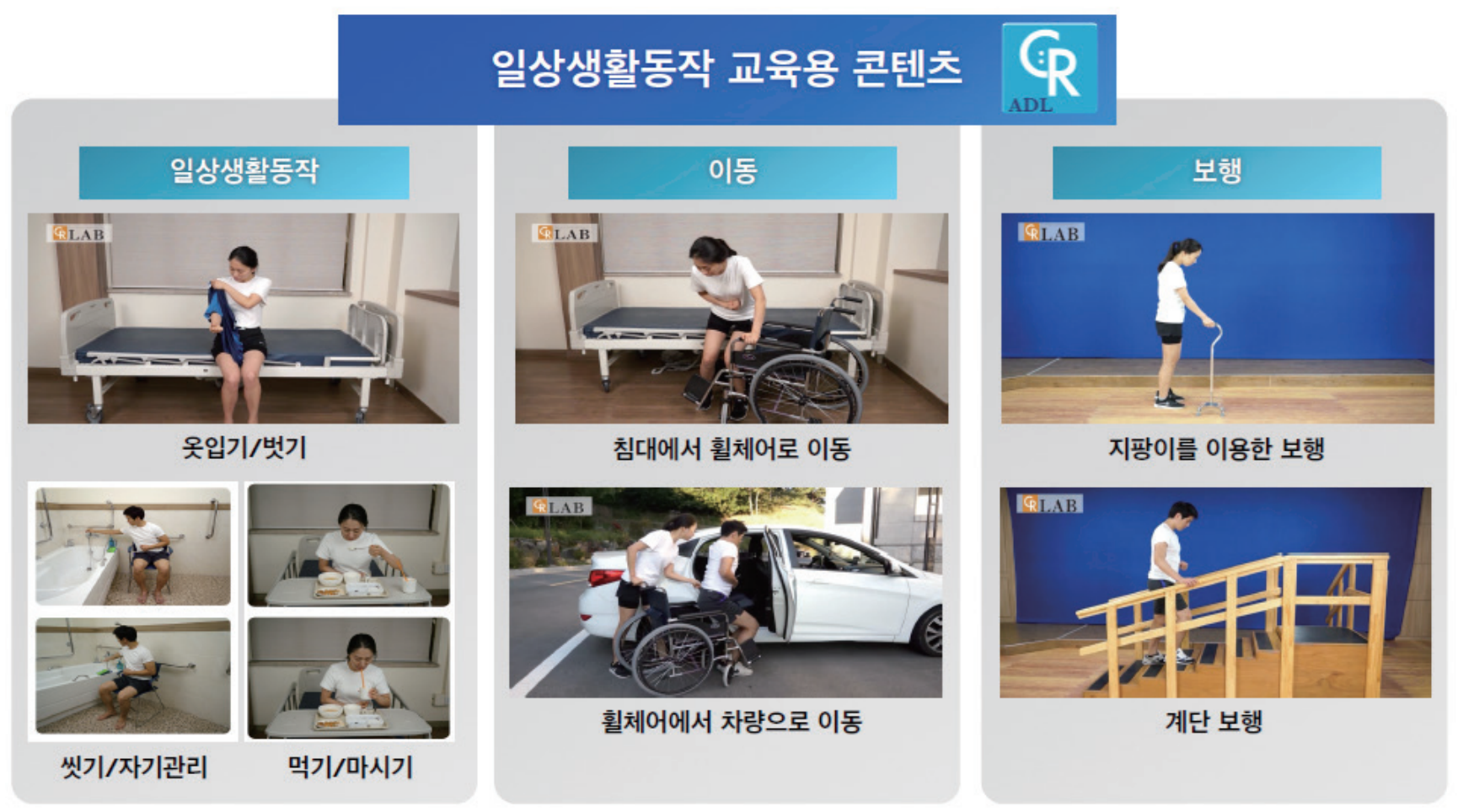

Figure 3. The picture of activities of dailiy living education contents for mobile

Table 4. Questionnaire

Question Contents $\quad$ Not at all Not like that Average Yes It really is
1. Was the description easy to understand while using this service?
2. Was the color or size of the text that appeared while using this service easy to read?
3. Did it take a long time to use the service?
4. Was the system difficult to use?
5. Did you feel that you were manipulating the system yourself?
6. Will you continue to use this service for rehabilitation purposes?
7. Will you use this service in addition to rehabilitation?
8. Does the description of the mission of this service accurately describe it?
9. Was it easier for you to get a description from someone else instead of the phrase from this service?
10. Was it realistic to use this service?
11. Did you feel immersed when using this service?
12. Did you feel uncomfortable or uncomfortable while using this service?
13. Were you having fun while using this service?


하게 함으로써 개별 사용자의 주관적인 만족도를 데이터로 얻었다. 설문조사는 닐슨의 의료용 증강현실 시스템 평가 측정항목을 본 서 비스에 맞도록 수정하여 13 개의 항목으로 제시하였다(Table 4). ${ }^{20}$

\section{결 과}

\section{1. 대상자의 일반적 특성}

본 연구의 사용성 평가에 참여한 대상자는 일반노인 11 명, 뇌졸중 환 자 7명, 편측무시 뇌졸중 환자 4 명이고, 재활전문가는 11 명이 참여하 였다. 대상자의 일반적 특성은 Table 5 와같다.

\section{2. 설문내용 분석}

본 연구의 설문내용 분석은 사용된 측정항목의 기술통계를 확인하 기 위하여 평균, 표준편차, 최소값, 최대값, 왜도 및 첨도를 분석하였 다. 설문내용 항목 중 1 번, 3 번, 4 번, 8 번, 9 번 문항 같은 경우 콘텐츠의 이해도와 난이도에 관련된 설문내용으로 평균값이 4-5점 사이로 나 타났다. 설문 항목 중 2 번, 5 번, 10 번 11 번 문항은 생생함과 상호작용, 몰입감에 관련된 설문 내용으로 평균값이 3-4점 사이로 나타났다. 6
번, 7번, 13 번 문항은 재미와 관련된 내용으로 3.9-5점 사이로 나타났 다(Table 6).

\section{고 찰}

본 연구를 통하여 뇌졸중 환자들이 병원 또는 가정에서 쉽게 이용할 수 있는 가상현실 기반 시지각중심 인지재활 서비스를 제공할 수 있 는 서비스를 개발하였다. 본 연구의 목적은 뇌졸중 환자를 대상으로 상지기능, 시지각, 인지와 관련된 훈련을 수행하기 위하여 ICF 항목으 로 구성된 가상현실기반 콘텐츠를 제공하는 서비스를 제작하여 뇌 졸중 환자의 기능증진에 도움이 되고자 함이다.

국내에서 최근 가상현실 재활 프로그램 대부분의 연구와 일상생 활활동과 관련이 없는 단순한 게임으로 구성된 연구와 프로그램이 대다수이다. 본 연구에서는 ICF 항목으로 구성된 가상현실 기반 콘 텐츠를 일상생활 활동과 밀접한 활동인 $\mathrm{d} 230$ 일상생활 이행, $\mathrm{d} 4$ 이동, $\mathrm{d} 6$ 가정생활, $\mathrm{d} 8$ 주요생활영역에서 환자들이 필요로 하는 항목을 재 활전문가들의 그룹 회의를 통해 도출하여 개발하였다.

본 연구의 사용성 평가 결과 콘텐츠 이해도와 난이도에 관련된 설

Table 5. General characteristics of the subject

\begin{tabular}{llccc}
\hline Characteristic & & Old man $(\mathrm{n}=11)$ & Stroke patients $(\mathrm{n}=7)$ & Unilateral neglected patients $(\mathrm{n}=4)$ \\
\hline Gender & Male & 3 & 7 & 2 \\
& Female & 8 & 0 & 2 \\
Paralyzed side & Left & - & 3 & 4 \\
& Right & - & 4 & 0 \\
Stroke type & Infarction & - & 5 & 1 \\
& Hemorrhage & - & $41 \pm 35.67$ & 3 \\
Mean duration & & - & $58.14 \pm 12.79$ & $20.5 \pm 11.67$ \\
Average age (year) & & $68.18 \pm 1.6$ & $59 \pm 9.2$ \\
MMSE-K (score) & & $28.91 \pm 0.94$ & $26.71 \pm 1.49$ & $25.75 \pm 1.5$ \\
\hline
\end{tabular}

Table 6. Analysis of questionnaire

\begin{tabular}{|c|c|c|c|c|c|}
\hline Questionnaire & Minimum value & Maximum value & Mean $\pm S D$ & Skewness & Kurtosis \\
\hline 1 & 2 & 5 & $4.05 \pm 0.99$ & -1.04 & 0.36 \\
\hline 2 & 1 & 5 & $3.95 \pm 1.13$ & -1.20 & 1.00 \\
\hline 3 & 1 & 5 & $2.27 \pm 1.25$ & 0.74 & 0.15 \\
\hline 4 & 1 & 4 & $2.32 \pm 0.94$ & 0.39 & -0.52 \\
\hline 5 & 1 & 5 & $4.00 \pm 0.92$ & -1.58 & 4.28 \\
\hline 6 & 1 & 5 & $3.91 \pm 1.06$ & -1.36 & 1.81 \\
\hline 7 & 1 & 5 & $3.95 \pm 1.04$ & -1.27 & 1.91 \\
\hline 8 & 2 & 5 & $4.36 \pm 0.79$ & -1.42 & 2.49 \\
\hline 9 & 1 & 5 & $4.18 \pm 1.14$ & -1.66 & 2.26 \\
\hline 10 & 2 & 5 & $4.27 \pm 0.98$ & -1.26 & 0.69 \\
\hline 11 & 2 & 5 & $4.23 \pm 0.92$ & -1.29 & 1.34 \\
\hline 12 & 1 & 5 & $1.50 \pm 1.01$ & 2.42 & 6.28 \\
\hline 13 & 1 & 5 & $4.14 \pm 1.08$ & -1.53 & 2.36 \\
\hline
\end{tabular}


문내용으로 평균값이 4-5점 사이로 높은 수치를 나타냈으며, 이와같 은 결과는 콘텐츠에서 제공하는 자막과 치료사에 의한 설명이 실험 참가자들의 콘텐츠 사용에 있어 이해도를 높게 해주는 것으로 보였 고, 난이도는 일반노인과 뇌졸중 환자들이 사용하기에 적당한 난이 도로 구성된 것으로 나타났다.

설문항목 중 2 번, 5 번, 10 번, 11 번 문항은 현실감과 상호작용, 몰입감 에 관련된 설문내용으로 평균값이 3.95로 높은 수치를 나타냈으며, 이와 같은 결과는 본 서비스의 가상현실 기술에 대하여 실험 참가자 들이 전반적으로 콘텐츠의 생생함과 현전감(presence) 등을 강하게 느꼈기 때문으로 생각된다.

6 번, 7 번 13번 문항은 재활목적과 본 서비스의 재미에 관련된 설문 내용으로 평균값이 3.9 이상 높은 수치를 나타냈으며, 이와 같은 결과 는 실험 참가들 대부분이 재활 목적과 재활 목적 이외의 재미 요소 로서 본 콘텐츠를 이용하고자 하는 것으로 보여진다. 또한, 12 번 항목 인 사이버 멀미에 관한 항목에서는 85 세의 뇌졸중 환자 1 명을 제외한 모든 참가자들이 어지러움증이나 멀미증상이 나타나지 않는다고 설 문조사와 인터뷰 과정에서 응답해주었다. 이는 본 서비스의 사이버 멀미 증상을 줄이기 위한 소프트웨어 및 하드웨어 구성의 결과로 사 료된다.

본 연구 결과를 바탕으로 가상현실 기반 콘텐츠는 일반노인, 뇌졸 중 환자 및 재활 전문가들의 사용성과 실용성, 만족도가 높은 것으로 나타났다. 가상현실 재활은 $2 \mathrm{D}$ 화면으로 구성되어 실제 환경과 유사 하지 못하는 제한점이 있었으나, 본 연구의 가상현실 서비스는 HMD 와 콘트롤러를 이용하여 실제환경과 비슷한 환경을 가상현실로 구 현할 수 있었다. 또한 가정환경과 유사한 가상현실공간에서 다양한 활동을 통해서 사용자들의 몰입감을 증가시키고 흥미와 동기를 유 발시킬 수 있었다. 본 연구는 몇 가지 제한점을 가지고 있다. 11 명의 일 반 노인과 11 명의 뇌졸중 환자, 11 명의 재활전문가를 대상으로 사용 성 평가를 시행하였기 때문에 연구결과를 모든 환자와 재활전문가 들에게 일반화시키는데 제한점이 있다. 향후 뇌졸중 환자에게 가상 현실 훈련콘텐츠를 적용하여 신체 및 인지기능에 미치는 영향에 대 한 많은 연구가 이루어져야 할 것이다.

\section{ACKNOWLEDGEMENTS}

이 논문은 2017년도 정보통신산업진흥원 의료ICT융합 컨소시엄 과제의 재원으로 지원을 받아 수행된 연구임(No. ITAC1606170110070001000200200)

\section{REFERENCE}

1. Trombly CA, Radomski MV, Trexel C et al. Occupational therapy and achievement of self-identified goals by adults with acquired brain injury. AJOT. 2002;56(5):489-98.

2. Gordon WA, Hibbard MR, Egelko S et al. Perceptual remediation in patients with right brain damage: A comprehensive program. Arch Phys Med Rehabil. 1985;66(6):353-9.

3. Feys HM, De Weerdt WJ, Selz BE et al. Effect of a therapeutic intervention for the hemiplegic upper limb in the acute phase after stroke. Stroke.1994;29(4)785-92.

4. Mercier L, Audet T, Hebert R et al. Impact of motor, cognitive and percepual disorders on ability to perform activies of daily living after stroke. Journal of Stroke. 2001;32:2602-8,

5. Kim HY, Heo M, Kim DW et al. Smartphone application program development to improve upper extremity function after stroke, Korea Entertainment Industry Association, 2015;9(2):363-9

6. Richard AA, David EM, Sylvan K. Eye-hand coordination oculomotor control in rapid aimed limb movements. Journal of Experimental Psychology: Human perception and performance. 1990;16(2):248-67

7. Shumway-Cook A, Woollacott M. Aging and postural control. motor control: theory and practical applications, 2nd, Baltimore, Williams \& Wilkins. 2001:222-247.

8. Lee JA, Lee HM. The effect of dual task training based on the international classification of functioning, disability, and health on walking ability and self-efficacy in chronic stroke. J Korean Sic Phys Med, 2017; 12(1):121-9.

9. Dobkin BH. Training and exercise to drive post stroke recovery. Nature clinical practice neurology. 2008;4(2):76-85.

10. Kim WJ, Chang MY, Kwon HC et al, Developing a model for the establishment of criteria concerning korean style activities of daily living training rooms in the field of occupational therapy. The journal of Korean society of occupational therapy. 2010;18(2):63-77.

11. Deutsch JE, Merians AS, Adamovich S et al. Development and application of virtual reality technology to improve hand yse and gait of individuals post stroke. Restorative neurology and neuroscience. 2004;22(35):371-86

12. Crosbie JH, Lennon S, Basford JR et al. Virtual reality in stroke rehabilitation: still more virtual than real. Disabil Rehabil, 2007;29(14):1139-46.

13. Rizzo AA, Buckwalter JG, Neumann U. Virtual reality and cognitive rehabilitation: a brief review of the future. The Journal of head trauma rehabilitation. 1997;12(6):1-15.

14. Baram Y, Aharon Peretz J, Lenger R. Virtual reality feedback for gait improvement in patients with idiopathic senile gait disorders and patients with history of stroke. J Am Geriatr Soc, 2010;58(1):191-2.

15. Rand D, Weiss PL, Katz N. Training multitasking in a virtual supermarket: a novel intervention after stroke. Am J Occ Ther, 2009;63(5):535-42.

16. Kim JH, Jang SH, Kim CS et al. Use of virtual reality to enhance balance and ambulation in chronic stroke: a double-blind, Randomized controlled study. Am J Phys Med Rehabil. 2009;88(9):693-701.

17. Merians AS, Tunik E, Adamovich SV. Virtual reality to maximize function for hand and arm rehabilitation: exploration of neural mechanisms. Stud Health Technol Inform. 2009;145:109-25. 
18. Hiltunen M, Laukka M, Luomala J. Mobile user experience. Ediita, IT press. 2002

19. Song YH, Jung CW, Lee HM. Development of and application for activities of daily living guidelines for stroke patients and caregivers. Korea
Entertainment Industry, Association, 2017;11(5):245-52.

20. Nilsson S, Johansson B. Fun and usable: augmented reality instructions in a hospital setting. , Sydney, 18th Australasian conference on Computer-Human Interaction: Entertaining user interfaces. 2007 